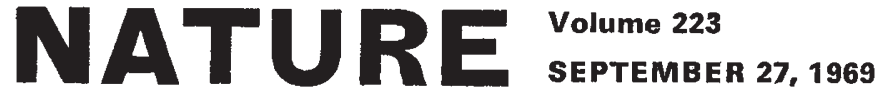

\section{No Ticket to Mars}

THe task force under Vice-President Agnew which has been worrying about the future course of the United States space programme has found a judicious compromise-between the owls and the eagles. For one thing, the group avoids a commitment to those who would like to see a steadily reducing budget for space activities by pointing out that a substantial reduction in the NASA budget could onJy be achieved by a reduction of the manned space flight programme to the point at which it would not be viable. By the same token, however, the group has implicitly rejected the view that there should be an American or two on Mars by 1981. It recognizes the value of definite and even outrageous goals as ways of making technical efforts hang together, but it soberly points out that it is possible to set off for Mars more or less every other year, and that there would be no shame in postponing the flight to Mars until later in the century. On balance, it is a sensible course to follow.

What the task force--which included Dr Robert C. Seamans (secretary of the Air Force), Dr Thomas O. Paine (acting administrator of NASA) and Dr Lee DuBridge (the President's science adviser)- has recommended is that the next few years should see a deliberate attempt to exploit the advantages which have been gained in the past decade, keeping more or less within. the present NASA budget for the next four years or so. At this level, it seems that NASA would be able to carry out many of the plans on which it has recently set its heart. For one thing, there would be a steady stream of journeys to the Moon. Such a budget would permit an increase in the scale of expenditure on scientific work with unmanned satellites, as well as the refinement of some kinds of satellite applicationsweather satellites, for example. (It is a pity that the Task Force seems also to have swallowed NASA's bait on what are called earth resources satellites.) Then, in 1972 or thereabouts, it would be possible for NASA to embark simultaneously on a scheme for constructing re-usable rockets for travelling between the Earth and satellite in orbit and the creation of a space station that would function as an outer terminal. On this plan, the NASA budget would rise (at present prices) to close on $\$ 6,000$ million by 1976 (compared with less than $\$ 4,000$ million now). A decision on the visit to Mars would be taken in 1978, and would increase the annual budget to $\$ 8,000$ million in the early 1980 s.

Undoubtedly the Task Force is right in choosing this middle path, although the reasons for its strategy are much more open to complaint. The truth is that it would have been a waste of what has been accomplished in the past few years to let the space programme run down, and in particular to give up the flights by people to the Moon. Nobody quite knows what will be accomplished, but it is a prudent insurance to keep the wheel turning slowly. But by the same test, there is no case for a rapid expansion of the programme, and in particular no case for an expedition to Mars. It is true, of course, that somebody may hit on a good reason for such a journey next year or the year after, but until that happens, waiting and seeing is the best policy. All that makes sense. It is a pity that the Task Force has muddied the waters with high-sounding talk of how this "balanced programme" will "promote a sense of world community through a programme which provides opportunity for broad international participation and cooperation". To the extent that this reflects Dr Paine's determination to strengthen the external relations of NASA, fine and dandy. To the extent that it may become a mirage which diverts the NASA's programme from realistic goals, it could be a danger. The people in Europe who planned ELDO and ESRO will have useful tales to tell on that.

If the recommendations of the Task Force are sensible enough, however, there are some unfortunate gaps in the study of the space programme which has now been carried out. There is, for example, the question of how the internal structure of NASA should be reorganized. In the hectic years leading to Apollo, it was natural, if unfortunate, that the landing on the Moon should have coloured many other branches of the administration's activity. One obvious defect has been in the planning of the purely scientific work based usually on unmanned satellites. Although NASA has done wonders in the short spell of its existence, there remains a nasty suspicion that the benefits would have been much greater if the funds available had been spent with more discretion. Are the results of the Biosatellite programme - the last satellite killed a monkey-worth the money spent on them, for example? And is it in the best interest of the scientific programme that NASA spending in the universities should have declined substantially in the past few years (at the same time as its own excellent research institutes have grown)? The chances are that there would be a much more effective use of scientific satellites if there were a more intimate relationship between NASA and the scientific community.

It is also important that NASA should devise ways of strengthening its links with similar organizations elsewhere. The Task Force would like to involve foreign scientists in the planning of the United States space programme as well as a division of labour on particular projects such as the development of directbroadcasting television satellites. The Task Force even goes so far us to spell out ways in which it would be possible for the United States to collaborate with the Soviet Union. Although much of what the Task Force has to say about international projects like these may be kite flying it will be interesting to see who is the first to respond-the President or the potential bencficiaries elsewhere. 